\title{
Redox Regulation of Calcium Signaling in Cancer Cells by Ascorbic Acid Involving the Mitochondrial Electron Transport Chain
}

\author{
Grigory G. Martinovich, Elena N. Golubeva, Irina V. Martinovich, \\ and Sergey N. Cherenkevich \\ Department of Biophysics, Belarusian State University, Nezavisimosti Avenue 4, 220030 Minsk, Belarus \\ Correspondence should be addressed to Grigory G. Martinovich, martinovichgg@bsu.by
}

Received 29 August 2012; Revised 29 October 2012; Accepted 29 October 2012

Academic Editor: Eaton Edward Lattman

Copyright (C) 2012 Grigory G. Martinovich et al. This is an open access article distributed under the Creative Commons Attribution License, which permits unrestricted use, distribution, and reproduction in any medium, provided the original work is properly cited.

\begin{abstract}
Previously, we have reported that ascorbic acid regulates calcium signaling in human larynx carcinoma HEp-2 cells. To evaluate the precise mechanism of $\mathrm{Ca}^{2+}$ release by ascorbic acid, the effects of specific inhibitors of the electron transport chain components on mitochondrial reactive oxygen species (ROS) production and $\mathrm{Ca}^{2+}$ mobilization in HEp-2 cells were investigated. It was revealed that the mitochondrial complex III inhibitor (antimycin A) amplifies ascorbate-induced $\mathrm{Ca}^{2+}$ release from intracellular stores. The mitochondrial complex I inhibitor (rotenone) decreases $\mathrm{Ca}^{2+}$ release from intracellular stores in HEp-2 cells caused by ascorbic acid and antimycin A. In the presence of rotenone, antimycin A stimulates ROS production by mitochondria. Ascorbate-induced $\mathrm{Ca}^{2+}$ release in HEp-2 cells is shown to be unaffected by catalase. The results obtained suggest that Ca ${ }^{2+}$ release in $\mathrm{HEp}-2$ cells caused by ascorbic acid is associated with induced mitochondrial ROS production. The data obtained are in line with the concept of redox signaling that explains oxidant action by compartmentalization of ROS production and oxidant targets.
\end{abstract}

\section{Introduction}

Redox processes involving transfer of electrons or hydrogen atoms are central processes of energy conversion in respiratory organisms. Recently, it has become apparent that numerous functionally significant biological processes proceed with participation of physical mechanisms ensuring intermolecular electron transfer. Electron transfer between low-molecular weight components of cytosol and intracellular proteins leads to the change of a functional state of both cellular proteins and cells as a whole $[1,2]$. All biological systems contain redox elements that play an important role in transcriptional regulation, cell proliferation, apoptosis, hormonal signaling, and other fundamental cell functions [3]. Organization and coordination of the redox activity of these elements occur through redox circuits and depend on the intracellular concentration of redox-active molecules $[4,5]$. Redox active molecules may cause both regulatory and toxic effects depending on the value of cellular redox state parameters $[5,6]$. However, little is known about mechanisms of regulation, structural organization, and interaction between electron-transport participants inside the cell and other signal and regulatory systems.

Recently new effects of such a redox-active molecule as ascorbic acid have been found. Beside numerous regulatory properties (hydroxylation of collagen, biosynthesis of carnitine and noradrenaline, etc.), selective cytotoxicity of high concentrations of ascorbic acid towards cancer cells has been described. Ascorbic acid in concentrations of 1$10 \mathrm{mM}$ was shown to induce the death of prostate cancer cells, stomach cancer cells, and acute myeloid leukemia cells $[7,8]$. In experiments in vitro, ascorbate cytotoxicity $\left(\mathrm{EC}_{50}<\right.$ $4 \mathrm{mM}$ ) was observed in many types of cancer cell lines, whereas normal cells were resistant $[9,10]$. Ascorbic acid treatment in high pharmacological concentrations significantly impeded tumor progression in vivo without toxicity 
to normal tissues $[11,12]$. Thus, ascorbic acid at high doses possesses anticancer properties, but mechanisms of its selective cytotoxicity and targets of its action are still obscure.

It was shown that in the presence of transition metal ions and ascorbic acid, $\mathrm{H}_{2} \mathrm{O}_{2}$ is formed [13]. These data suggest that ascorbate cytotoxicity may be due to its ability to generate $\mathrm{H}_{2} \mathrm{O}_{2}[7,12]$. But this hypothesis does not appear to be compatible with facts. Recent studies have indicated that the intravenous injection of ascorbic acid in high (up to $8 \mathrm{mM}$ ) concentrations was not accompanied by the formation of $\mathrm{H}_{2} \mathrm{O}_{2}$ in blood [14]. It was also shown that even in the presence of transition metal ions and $\mathrm{H}_{2} \mathrm{O}_{2}$, ascorbate acted as an antioxidant that prevented lipid peroxidation in human plasma in vitro [15]. Previously, we have found that ascorbic acid regulates calcium signaling in human larynx carcinoma cells [16]. Ascorbate at concentrations in the range $3-10 \mathrm{mM}$ activated cytosol $\mathrm{pH}$ value decrease and $\mathrm{Ca}^{2+}$ release from thapsigargin-sensitive intracellular $\mathrm{Ca}^{2+}$ stores. Although the ability of ascorbic acid to induce $\mathrm{Ca}^{2+}$ mobilization is shown, the precise mechanisms involved in $\mathrm{Ca}^{2+}$ release are not known. We proposed that mitochondria can be involved in ascorbate-induced calcium signaling. The aim of this study was to explore the participation of mitochondrial enzymes in regulation of calcium signaling in human larynx carcinoma HEp-2 cells by ascorbic acid.

\section{Methods and Materials}

2.1. Cell Culture and Reagents. Ascorbic acid was obtained from Himhrom Ltd. (Minsk, Belarus). Dulbecco's modified Eagle's medium (DMEM), fura-2-acetoxymethyl (AM) ester, $2^{\prime}, 7^{\prime}$-dichlorodihydrofluorescein diacetate $\left(\mathrm{H}_{2} \mathrm{DCF}\right.$ $\mathrm{DA})$, rotenone, antimycin A, catalase, and HEPES were purchased from Sigma-Aldrich (St. Louis, MO, USA). Human larynx carcinoma HEp-2 cells were purchased from the Republican Research and Practical Center for Epidemiology and Microbiology (Minsk, Belarus). The cells were cultured at $37^{\circ} \mathrm{C}$ under a humidified atmosphere with $5 \% \mathrm{CO}_{2}$ in DMEM supplemented with $10 \%$ fetal calf serum, $2 \mathrm{mM}$ glutamine, and $80 \mathrm{mg} / \mathrm{mL}$ gentamicin. Rotenone (50-150 $\mu \mathrm{M})$, antimycin $\mathrm{A}(5-40 \mu \mathrm{M})$, ascorbate $(3-10 \mathrm{mM})$, and catalase $(500 \mathrm{U} / \mathrm{mL})$ were used.

2.2. Fluorescent Spectrofluorimetry. Measurements of the free calcium ions' cytosol concentration $\left(\left[\mathrm{Ca}^{2+}\right]_{\text {cyt }}\right)$ were performed as previously described [17]. HEp-2 cells were loaded with $2.5 \mu \mathrm{M}$ fura-2 AM, washed, and mounted under continuous stirring in the chamber of the spectrofluorimeter (LSF 1211A, Minsk, Belarus). The standard recording medium (KRH) contained $131 \mathrm{mM} \mathrm{NaCl}, 5 \mathrm{mM} \mathrm{KCl}, 1.3 \mathrm{mM} \mathrm{CaCl}$, $1.3 \mathrm{mM} \mathrm{MgSO}_{4}, 6 \mathrm{mM}$ glucose, and $20 \mathrm{mM}$ HEPES, pH 7.4 $(\mathrm{NaOH})$.

Intracellular ROS generation was recorded using $\mathrm{H}_{2}$ DCF-DA, which is a nonpolar compound that is converted into a nonfluorescent polar derivative $\left(\mathrm{H}_{2} \mathrm{DCF}\right)$ by cellular esterases after incorporation into cells. Membrane-impermeable $\mathrm{H}_{2} \mathrm{DCF}$ is rapidly oxidized to highly fluorescent $2^{\prime}, 7^{\prime}$-dichlorofluorescein (DCF) in the

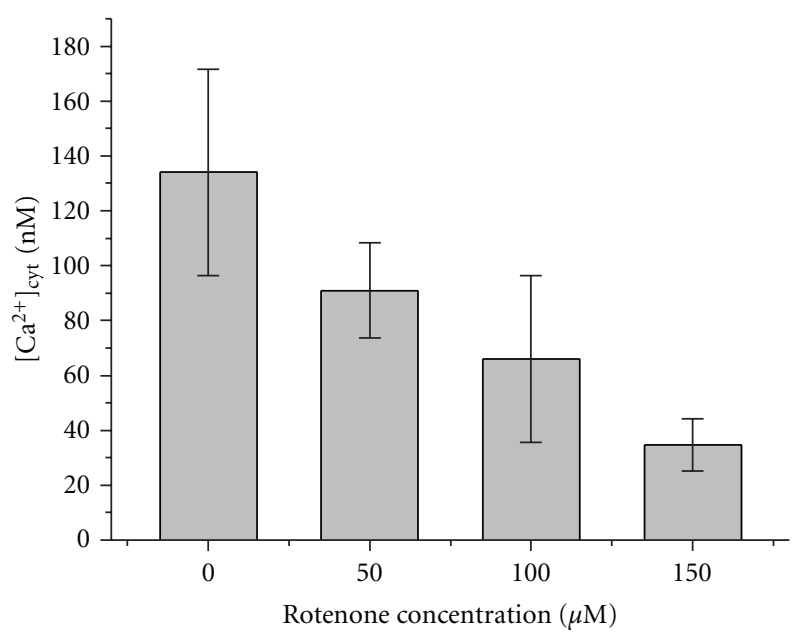

FIGURE 1: Influence of rotenone on ascorbate-induced increase of $\left[\mathrm{Ca}^{2+}\right]_{\text {cyt }}$ in HEp-2 cells. Concentration of ascorbic acid in KRH$5 \mathrm{mM}$. Number of cells in $1 \mathrm{~mL}-2.5 \times 10^{6}$.

presence of intracellular ROS [18]. After loading with $10 \mu \mathrm{M}$ $\mathrm{H}_{2}$ DCF-DA for $30 \mathrm{~min}$, HEp-2 cells were rinsed two times with $\mathrm{KRH}$ and DCF fluorescence intensity was measured using $488 \mathrm{~nm}$ excitation $/ 530 \mathrm{~nm}$ emission settings. All experiments were carried out at $37^{\circ} \mathrm{C}$.

2.3. Statistics. The data were expressed as means \pm standard error of the mean (SEM). Statistical significances between means were assayed using Student's $t$-test. The values were taken as significantly different when $P<0.05$.

\section{Results and Discussion}

In a previous study, ascorbic acid was found to cause a transient increase in $\left[\mathrm{Ca}^{2+}\right]_{\text {cyt }}$ in human larynx carcinoma HEp-2 cells accompanied by depletion of intracellular thapsigarginsensitive calcium stores [16]. Thapsigargin is known to induce $\mathrm{Ca}^{2+}$ release, from mitochondria and inositol-1,4,5triphosphate-responsive $\mathrm{Ca}^{2+}$ stores. To examine involvement of mitochondria in ascorbate-induced $\mathrm{Ca}^{2+}$ release we used rotenone, mitochondrial complex I inhibitor. It was shown that treatment of cells with rotenone led to the decrease of ascorbate-induced $\mathrm{Ca}^{2+}$ release in HEp-2 cells (Figure 1), indicating that participation of mitochondrial enzymes in ascorbate induces $\mathrm{Ca}^{2+}$ release. There is no evidence that any specific receptors for ascorbate exist in mitochondria. To explain participation of mitochondria in ascorbate-induced $\mathrm{Ca}^{2+}$ release, we proposed a mechanism according to which an increase in ascorbate concentration could intensify ROS production by mitochondrial enzymes.

It is generally accepted that superoxide anion $\left(\mathrm{O}_{2}^{--}\right)$is the primary free radical in mitochondria, which is formed as the result of electron "leak" from the electron transport chain elements to oxygen [19]. Ubisemiquinones generated in the respiratory chain were identified as possible donors of electrons for oxygen [20]. Here, it is reasonable to mention that ascorbate can reduce c-type cytochromes and b-type 


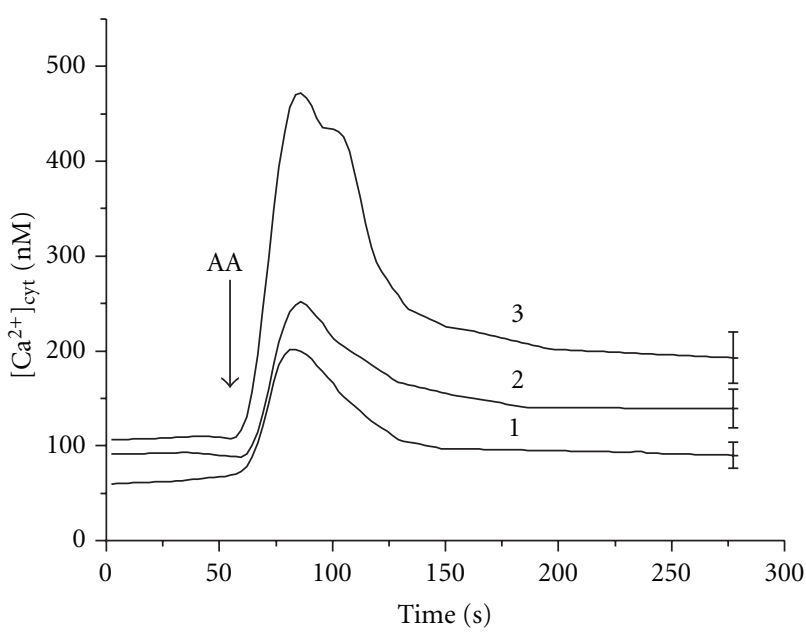

FIgURE 2: Influence of antimycin A on the ascorbate-induced $\mathrm{Ca}^{2+}$ release from HEp-2 cells mitochondria. Concentrations in $\mathrm{KRH}$ : ascorbic acid $-5 \mathrm{mM}$; antimycin $\mathrm{A}(\mu \mathrm{M}): 1-0,2-10,3-15$. Number of cells in $1 \mathrm{~mL}-3 \times 10^{6}$. The arrow shows the instant of ascorbate addition.

cytochromes $[21,22]$. The evidence, taken together, suggests that electron transfer from ascorbic acid to cytochrome $c_{1}$ or cytochrome $c$ should decrease electron flow from ubiquinol to Rieske iron-sulfur cluster resulting in a rise of ubisemiquinone concentration and superoxide production. Dismutation of $\mathrm{O}_{2}^{--}$by the mitochondrial matrix $\mathrm{Mn}$ superoxide dismutase leads to the formation of $\mathrm{H}_{2} \mathrm{O}_{2}$ [20]. $\mathrm{H}_{2} \mathrm{O}_{2}$, in turn, can oxidize thiol groups of targets and regulate $\mathrm{Ca}^{2+}$ release $[23,24]$. To exclude possible generation of $\mathrm{H}_{2} \mathrm{O}_{2}$ by ascorbate in the extracellular solution catalase was used. Ascorbate-induced $\mathrm{Ca}^{2+}$ release from mitochondria was shown to be unaffected by catalase in an concentration of $500 \mathrm{U} / \mathrm{mL}$ (not shown). Thus, the important point in our model is that ROS production by ascorbic acid proceeds nearby specific redox sensors.

According to the proposed model, the increase of ROS generation in mitochondria is thought to induce $\mathrm{Ca}^{2+}$ release. The impact of this mechanism was assessed by using mitochondrial complex inhibitors antimycin $\mathrm{A}$ and rotenone. The increase in $\left[\mathrm{Ca}^{2+}\right]_{\mathrm{cyt}}$ in HEp-2 cells was detected after the application of mitochondrial complex III inhibitor antimycin A in concentrations above $20 \mu \mathrm{M}$ (Figure 3, inset). On the other hand, the increase in the amplitude and duration of ascorbate-induced $\mathrm{Ca}^{2+}$ release was observed even at lower concentrations of antimycin A $(10 \mu \mathrm{M})$ used in the study (Figure 2). Moreover, after the addition of ascorbate to HEp-2 cell suspension, antimycin $\mathrm{A}$ in this concentration induced a significant increase in $\left[\mathrm{Ca}^{2+}\right]_{\text {cyt }}$. Subsequent addition of mitochondrial complex I inhibitor rotenone resulted in the decrease of $\left[\mathrm{Ca}^{2+}\right]_{\mathrm{cyt}}$ in cancer HEp-2 cells (Figure 3). These findings support our suggestion that ascorbate-induced $\mathrm{Ca}^{2+}$ release from HEp2 cells mitochondria proceeds with the participation of ROS produced in the electron transport chain.

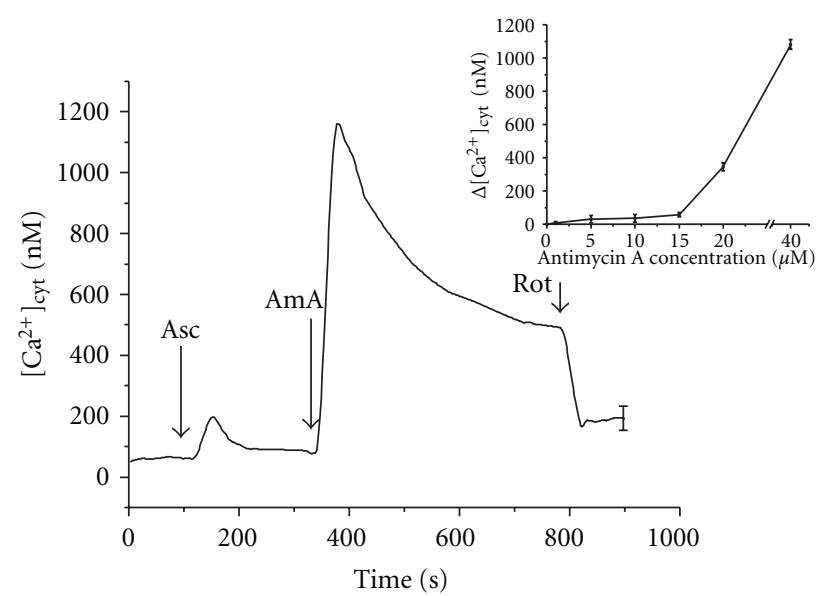

FiguRE 3: Influence of ascorbic acid and rotenone on the $\mathrm{Ca}^{2+}$ release from HEp-2 cells mitochondria under the antimycin A treatment. Concentrations in $\mathrm{KRH}$ : ascorbic acid- $5 \mathrm{mM}$, antimycin $\mathrm{A}-10 \mu \mathrm{M}$, rotenone $-50 \mu \mathrm{M}$. Number of cells in $1 \mathrm{~mL}-3 \times 10^{6}$. Arrows show the instants of antimycin A (AmA), ascorbic acid (Asc), and rotenone (Rot) addition. The inset shows dependence of increase in $\left[\mathrm{Ca}^{2+}\right]_{\text {cyt }}$ on the antimycin A concentration.

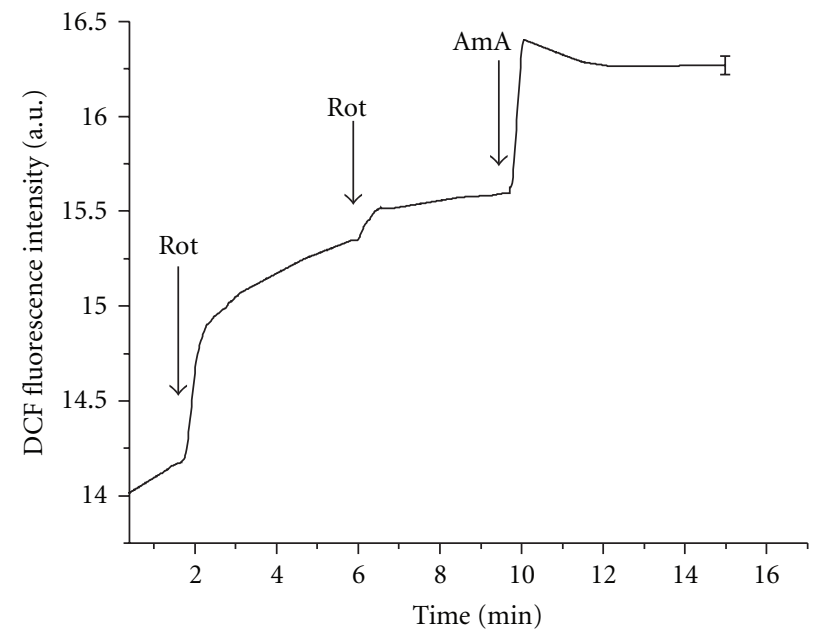

Figure 4: DCF fluorescence intensity in HEp-2 cells. Concentrations in KRH: rotenone- $50 \mu \mathrm{M}$, antimycin $\mathrm{A}-10 \mu \mathrm{M}$. Number of cells in $1 \mathrm{~mL}-3 \times 10^{6}$. Arrows show the instants of antimycin A $(\mathrm{AmA})$ and rotenone (Rot) addition.

The major sites of superoxide formation within the mitochondrial respiratory chain are linked to NADH: ubiquinone oxidoreductase (complex I) and ubiquinol: cytochrome c oxidoreductase (complex III) [19]. In our experiments both rotenone and antimycin A were ascertained to enhance ROS production in HEp-2 cells. Superoxide production by complex $\mathrm{I}$ is supposed to occur during the reverse electron transport (RET) from ubiquinol to $\mathrm{NAD}^{+}$and during the forward electron transport (FET) from $\mathrm{NADH}$ to ubiquinone, the former being faster than the latter. Recent observations have led to the conclusion that rotenone enhances ROS formation during the FET and inhibits it 


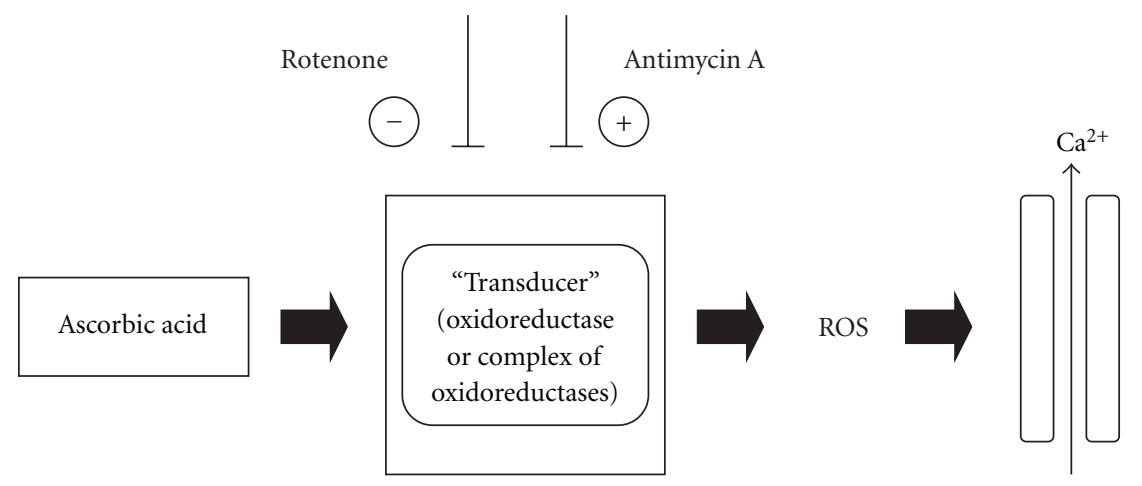

FIGURE 5: A schematic representation of the mechanism of ascorbate-induced redox regulation of $\mathrm{Ca}^{2+}$ release. Signal transduction form redox-active molecule to target occurs with additional participants—oxidoreductases (in our case-mitochondrial enzymes). Mitochondriaderived ROS induce $\mathrm{Ca}^{2+}$ release. Signal decoding in cells depends on the transducer activity of additional participant. Antimycin A may increase the ROS production and $\mathrm{Ca}^{2+}$ response in cells, while rotenone decreases it.

during the RET [19]. Moreover, the RET-induced ROS production is regulated by $\Delta \psi$. Generation of $\mathrm{O}_{2}^{--}$and $\mathrm{H}_{2} \mathrm{O}_{2}$ by the electron transport chain is amplified by an increase in $\Delta \psi$ [25]. The inhibition of electron transport by antimycin A in complex III resulted in ROS formation even after rotenone treatment (Figure 4). These results indicate that ROS formation by mitochondria in HEp2 cells under physiological conditions is not connected with the RET in complex I. The RET is observed under conditions of high $\Delta \psi$ [19]. Previously we have shown that ascorbate at high concentrations induces the decrease in intracellular $\mathrm{pH}$ value that can lead to the increase in $\Delta \psi$ [16]. In such conditions, rotenone inhibits ROS production in mitochondria. Therefore, rotenone decreased ascorbateinduced $\mathrm{Ca}^{2+}$ release (Figure 1) and antimycin A-induced $\mathrm{Ca}^{2+}$ release (Figure 3). The results obtained indicate that antimycin A activates ROS production by complex III leading to the increase in ascorbate-induced calcium response of HEp- 2 cells. Rotenone, in turn, decreases the rise in $\left[\mathrm{Ca}^{2+}\right]_{\mathrm{cyt}}$ caused by the action of ascorbate and antimycin $\mathrm{A}$ as it blocks electron transfer in complex I of the mitochondrial respiratory chain and inhibits the $\mathrm{H}_{2} \mathrm{O}_{2}$ production in complex III. Decrease in the intracellular $\mathrm{pH}$ value enhances oxidative processes in cells [26]; therefore after the ascorbate treatment, the increase in $\left[\mathrm{Ca}^{2+}\right]_{\text {cyt }}$ caused by antimycin A occurred even at low concentrations of the inhibitor (Figure 3). Taken together, our results suggest that ascorbic acid can regulate $\mathrm{Ca}^{2+}$ release in HEp-2 cells by locally induced ROS production.

The data of this preliminary study point out that complex III may be a possible player of ROS production in mitochondria under ascorbate treatment. It is important to emphasize that multiple sources of ROS generation have been identified in mitochondria $[27,28]$. Recently, proapoptotic protein $\mathrm{p} 66^{\text {Shc }}$ has been shown to localize in the mitochondrial intermembrane space and redox cycle with cytochrome $\mathrm{c}$ to produce $\mathrm{H}_{2} \mathrm{O}_{2}$ that induces permeability transition [29]. In conditions of rise of ascorbic acid concentration, activation of $\mathrm{p} 66^{\text {Shc }}$ pathways may in part explain enhancement of ROS generation. Further investigation will improve our understanding of mechanisms by which mitochondria are stimulated to produce oxidants and what the proximate targets of such oxidants are.

On the other hand, the results obtained indicate a new possible way of redox regulation of $\mathrm{Ca}^{2+}$ signaling (Figure 5). Calcium signaling occurs when the cell is stimulated to release $\mathrm{Ca}^{2+}$ from intracellular stores. According to our data, the antioxidant ascorbic acid can regulate $\mathrm{Ca}^{2+}$ release by mitochondria-derived ROS. Ascorbate-induced changes of intracellular redox state can be transduced in increase of ROS concentration by components of electron transport chain. Thus in the proposed mechanism of regulation in addition to redox-active molecules and their targets, an additional participant of signal transduction-oxidoreductases (components of electron transport chain)-appears. The important implication of mitochondrial enzymes in redox regulation is that in this case signal decoding in cells depends also on the "transducer" activity in different types of cells. Thus the redox modulation of $\mathrm{Ca}^{2+}$ sparks occurs in speciesand tissue-specific fashion. Some agents (antimycin A) may increase the ROS production and $\mathrm{Ca}^{2+}$ response in cells, while others (rotenone) decrease it (see Figure 5). Local ROS production modifies the amplitude of $\mathrm{Ca}^{2+}$ sparks that are sensed and decoded into defined cell actions by a broad variety of cellular effectors.

In general, results of our research are in agreement with the concept of redox signaling that explains oxidant action by compartmentalization of ROS production and oxidant targets [30]. Our observations lead to the conclusion that the key condition of ascorbate cytotoxicity is ROS generation by mitochondria. In these conditions, $\mathrm{Ca}^{2+}$ release proceeds as a result of local effects of mitochondrial oxidants.

Earlier was supposed that selectivity of ascorbate effect on cancer cells was mediated by an altered acid-base balance in tumor tissues [16]. Changes in the activity of electron transport chain components observed in many cancer cells including carcinoma cells [31] may also promote cytotoxic action of ascorbate towards cancer cells. Ascorbic acid, capable of regulating both acid-base and redox states of cancer cells, may serve as a prototype for the development 
of new anticancer agents with the mechanism of binary regulatory action. Therefore, a detailed understanding of the mechanism of ascorbate-induced ROS production could aid in the development of new anticancer strategies.

\section{Abbreviations}

$\Delta \psi: \quad$ Transmembrane electric potential difference

DCF: $\quad 2^{\prime}, 7^{\prime}$-Dichlorofluorescein

$\mathrm{H}_{2}$ DCF: $\quad 2^{\prime}, 7^{\prime}$-Dichlorodihydrofluorescein

$\mathrm{H}_{2}$ DCF-DA: $2^{\prime}, 7^{\prime}$-Dichlorodihydrofluorescein diacetate

FET: $\quad$ Forward electron transport

KRH: $\quad$ Krebs-Ringer-HEPES buffer

RET: $\quad$ Reverse electron transport

ROS: $\quad$ Reactive oxygen species.

\section{Acknowledgment}

This work was partially supported by a funding from the Belarusian Republican Foundation for Fundamental Research (B11-027).

\section{References}

[1] F. Rusnak and T. Reiter, "Sensing electrons: protein phosphatase redox regulation," Trends in Biochemical Sciences, vol. 25, no. 11, pp. 527-529, 2000.

[2] G. M. Ullmann and E. W. Knapp, "Electrostatic models for computing protonation and redox equilibria in proteins," European Biophysics Journal, vol. 28, no. 7, pp. 533-551, 1999.

[3] D. P. Jones, "Redox sensing: orthogonal control in cell cycle and apoptosis signalling," Journal of Internal Medicine, vol. 268, no. 5, pp. 432-448, 2010.

[4] D. P. Jones, "Radical-free biology of oxidative stress," American Journal of Physiology, vol. 295, no. 4, pp. C849-C868, 2008.

[5] G. G. Martinovich, I. V. Martinovich, and S. N. Cherenkevich, "Redox regulation of cellular processes: a biophysical model and experiment," Biophysics, vol. 56, no. 3, pp. 444-451, 2011.

[6] G. G. Martinovich, I. V. Martinovich, S. N. Cherenkevich, and H. Sauer, "Redox buffer capacity of the cell: theoretical and experimental approach," Cell Biochemistry and Biophysics, vol. 58, no. 2, pp. 75-83, 2010.

[7] S. Park, S. S. Han, C. H. Park et al., "L-Ascorbic acid induces apoptosis in acute myeloid leukemia cells via hydrogen peroxide-mediated mechanisms," International Journal of Biochemistry and Cell Biology, vol. 36, no. 11, pp. 2180-2195, 2004.

[8] Y. X. Sun, Q. S. Zheng, G. Li, D. A. Guo, and Z. R. Wang, "Mechanism of ascorbic acid-induced reversion against malignant phenotype in human gastric cancer cells," Biomedical and Environmental Sciences, vol. 19, no. 5, pp. 385-391, 2006.

[9] Q. Chen, M. G. Espey, M. C. Krishna et al., "Pharamacologic ascorbic acid concentrations selectively kill cancer cells: action as a pro-drug to deliver hydrogen peroxide to tissuse," Proceedings of the National Academy of Sciences of the United States of America, vol. 102, no. 38, pp. 13604-13609, 2005.

[10] Q. Chen, M. G. Espey, A. Y. Sun et al., "Pharmacologic doses of ascorbate act as a prooxidant and decrease growth of aggressive tumor xenografts in mice," Proceedings of the National Academy of Sciences of the United States of America, vol. 105, no. 32, pp. 11105-11109, 2008.
[11] S. Ohno, Y. Ohno, N. Suzuki, G. I. Soma, and M. Inoue, "High-dose vitamin C (ascorbic acid) therapy in the treatment of patients with advanced cancer," Anticancer Research, vol. 29, no. 3, pp. 809-815, 2009.

[12] H. B. Pollard, M. A. Levine, O. Eidelman, and M. Pollard, "Pharmacological ascorbic acid suppresses syngeneic tumor growth and metastases in hormone-refractory prostate cancer," In Vivo, vol. 24, no. 3, pp. 249-255, 2010.

[13] G. R. Buettner and B. A. Jurkiewicz, "Catalytic metals, ascorbate and free radicals: combinations to avoid," Radiation Research, vol. 145, no. 5, pp. 532-541, 1996.

[14] Q. Chen, M. G. Espey, A. Y. Sun et al., "Ascorbate in pharmacologic concentrations selectively generates ascorbate radical and hydrogen peroxide in extracellular fluid in vivo," Proceedings of the National Academy of Sciences of the United States of America, vol. 104, no. 21, pp. 8749-8754, 2007.

[15] J. Suh, B. Z. Zhu, and B. Frei, "Ascorbate does not act as a prooxidant towards lipids and proteins in human plasma exposed to redox-active transition metal ions and hydrogen peroxide," Free Radical Biology and Medicine, vol. 34, no. 10, pp. 13061314, 2003.

[16] G. G. Martinovich, I. V. Martinovich, and S. N. Cherenkevich, "Effects of ascorbic acid on calcium signaling in tumor cells," Bulletin of Experimental Biology and Medicine, vol. 147, no. 4, pp. 469-472, 2009.

[17] R. A. Hirst, C. Harrison, K. Hirota, and D. G. Lambert, "Measurement of $\left[\mathrm{Ca}^{2+}\right] \mathrm{i}$ in whole cell suspensions using fura2," Methods in Molecular Biology, vol. 312, pp. 37-45, 2006.

[18] X. Chen, Z. Zhong, Z. Xu, L. Chen, and Y. Wang, " 2 ', $7^{\prime}$ Dichlorodihydrofluorescein as a fluorescent probe for reactive oxygen species measurement: forty years of application and controversy," Free Radical Research, vol. 44, no. 6, pp. 587-604, 2010.

[19] G. Lenaz and M. L. Genova, "Structure and organization of mitochondrial respiratory complexes: a new understanding of an old subject," Antioxidants and Redox Signaling, vol. 12, no. 8, pp. 961-1008, 2010.

[20] S. Raha and B. H. Robinson, "Mitochondria, oxygen free radicals, disease and ageing," Trends in Biochemical Sciences, vol. 25, no. 10, pp. 502-508, 2000.

[21] A. I. Al-Ayash and M. T. Wilson, "The mechanism of reduction of single-site redox proteins by ascorbic acid," Biochemical Journal, vol. 177, no. 2, pp. 641-648, 1979.

[22] D. Njus, M. Wigle, P. M. Kelley, B. H. Kipp, and H. B. Schlegel, "Mechanism of ascorbic acid oxidation by cytochrome b561," Biochemistry, vol. 40, no. 39, pp. 11905-11911, 2001.

[23] A. P. Halestrap, K. Y. Woodfield, and C. P. Connern, "Oxidative stress, thiol reagents, and membrane potential modulate the mitochondrial permeability transition by affecting nucleotide binding to the adenine nucleotide translocase," The Journal of Biological Chemistry, vol. 272, no. 6, pp. 3346-3354, 1997.

[24] I. N. Pessah, K. H. Kim, and W. Feng, "Redox sensing properties of the ryanodine receptor complex," Frontiers in Bioscience, vol. 7, pp. a72-a79, 2002.

[25] A. A. Starkov and G. Fiskum, "Regulation of brain mitochondrial $\mathrm{H}_{2} \mathrm{O}_{2}$ production by membrane potential and $\mathrm{NAD}(\mathrm{P}) \mathrm{H}$ redox state," Journal of Neurochemistry, vol. 86, no. 5, pp. 1101-1107, 2003.

[26] G. G. Martinovich, I. V. Martinovich, E. N. Golubeva, and S. N. Cherenkevich, "Role of hydrogen ions in the regulation of the redox state of erythrocytes," Biofizika, vol. 54, no. 5, pp. 846-851, 2009. 
[27] A. Y. Andreyev, Y. E. Kushnareva, and A. A. Starkov, "Mitochondrial metabolism of reactive oxygen species," Biochemistry, vol. 70, no. 2, pp. 200-214, 2005.

[28] A. A. Starkov, "The role of mitochondria in reactive oxygen species metabolism and signaling," Annals of the New York Academy of Sciences, vol. 1147, pp. 37-52, 2008.

[29] M. Giorgio, E. Migliaccio, F. Orsini et al., "Electron transfer between cytochrome c and p66Shc generates reactive oxygen species that trigger mitochondrial apoptosis," Cell, vol. 122, no. 2, pp. 221-233, 2005.

[30] L. S. Terada, "Specificity in reactive oxidant signaling: think globally, act locally," Journal of Cell Biology, vol. 174, no. 5, pp. 615-623, 2006.

[31] H. Simonnet, N. Alazard, K. Pfeiffer et al., "Low mitochondrial respiratory chain content correlates with tumor aggressiveness in renal cell carcinoma," Carcinogenesis, vol. 23, no. 5, pp. 759$768,2002$. 

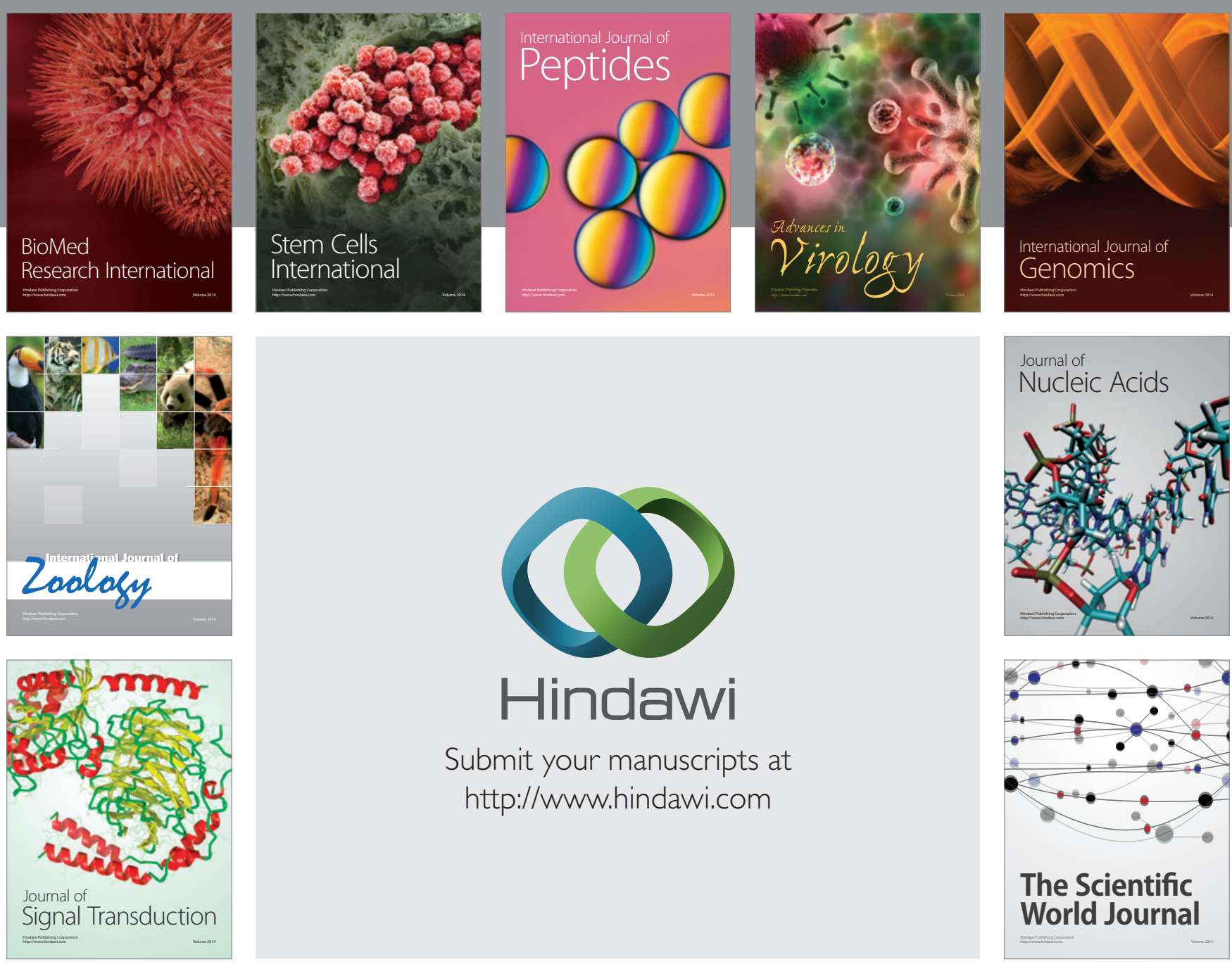

Submit your manuscripts at

http://www.hindawi.com
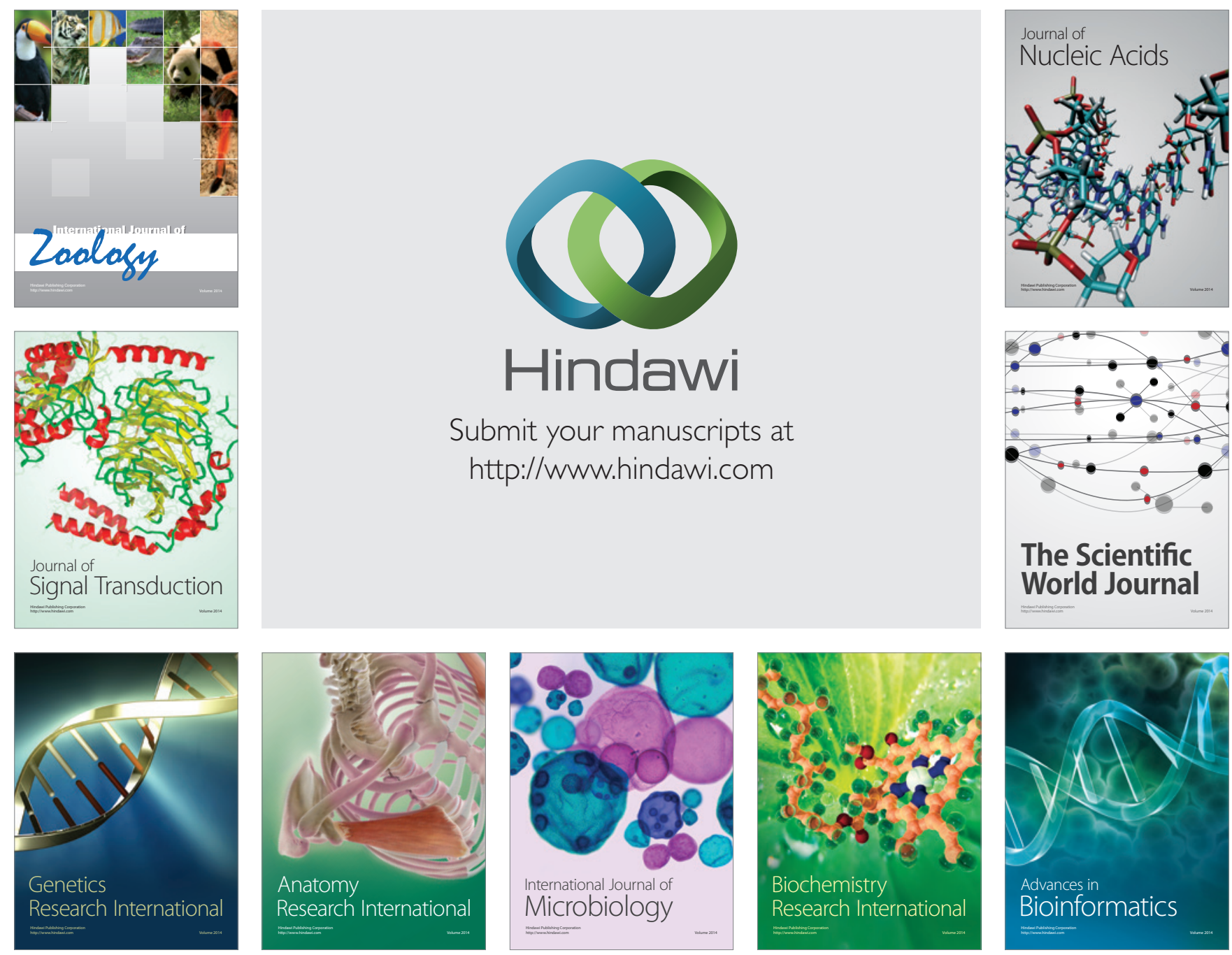

The Scientific World Journal
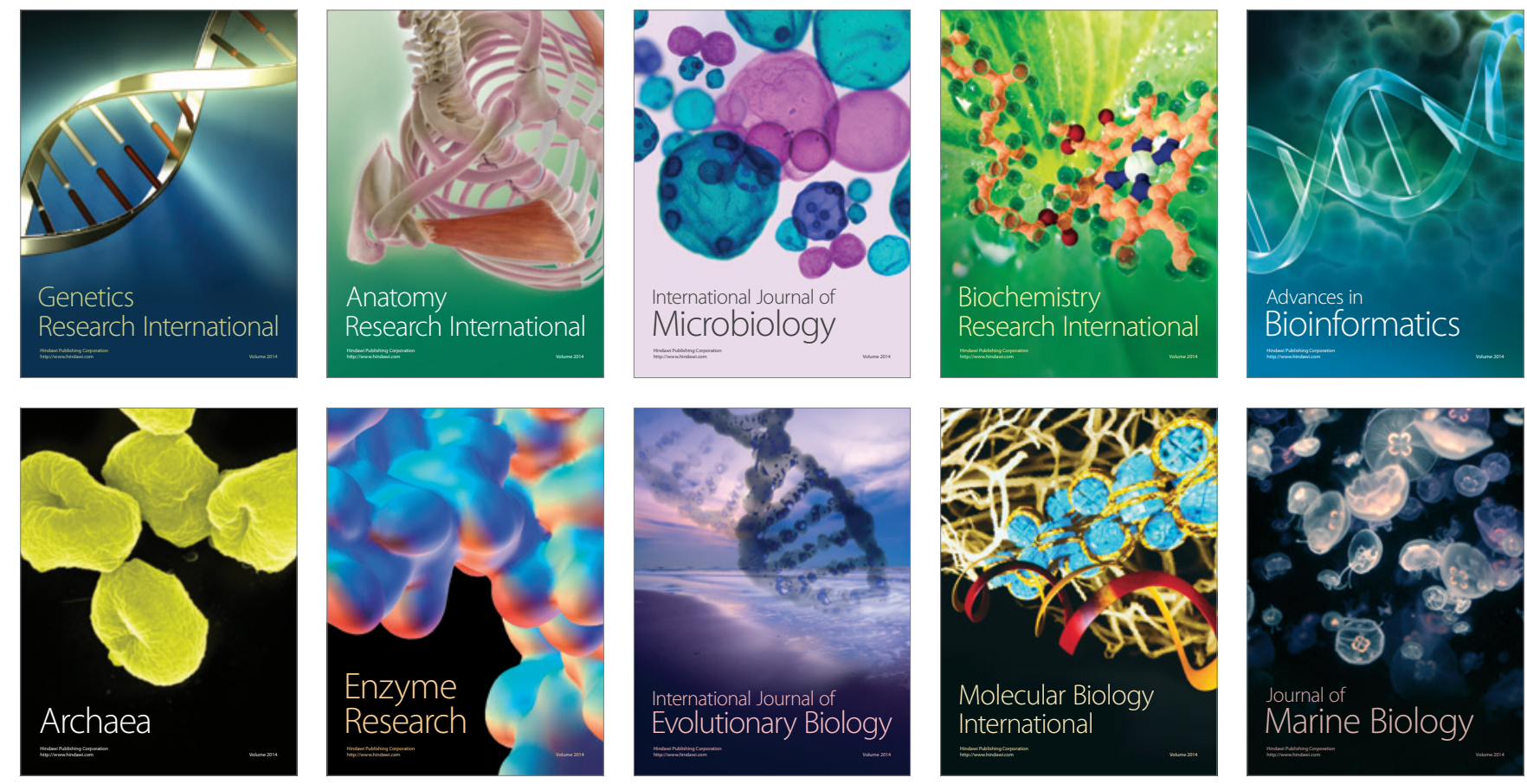